Human prophylactic vaccine adjuvants and their determinant role in new vaccine formulations

O. Pérez, A. Batista-Duharte, E. González, C. Zayas, J. Balboa, M. Cuello, O. Cabrera, M. Lastre and V.E.J.C. Schijns

The Brazilian Journal of Medical and Biological Research is partially financed by

\section{QRPPq}

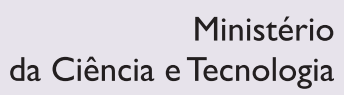

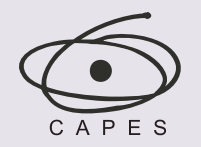

Ministério da Educação
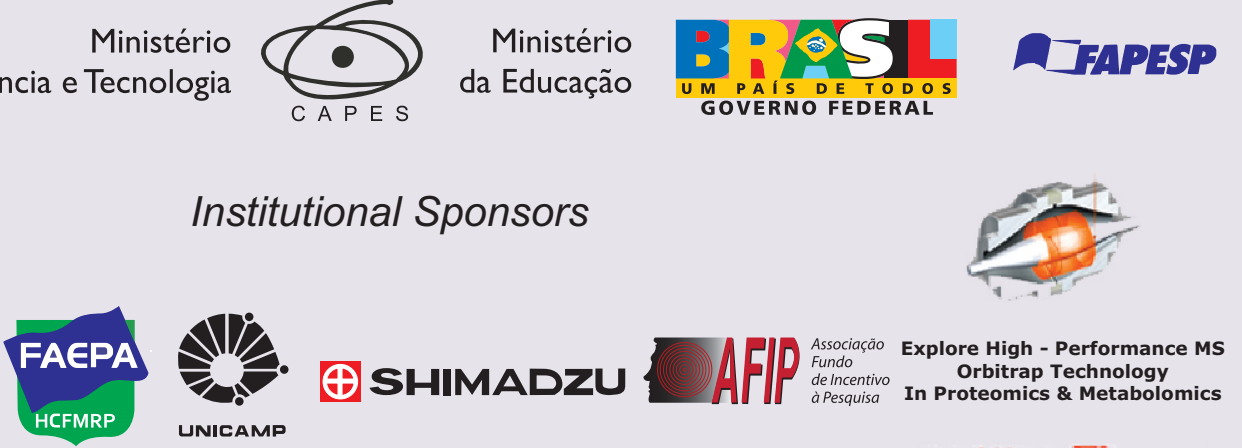

Institutional Sponsors

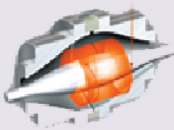

Ф SHIMADZU UNICAMP

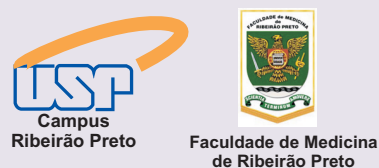




\title{
Human prophylactic vaccine adjuvants and their determinant role in new vaccine formulations
}

\author{
O. Pérez ${ }^{1}$, A. Batista-Duharte ${ }^{2}$, E. González ${ }^{1}$, C. Zayas ${ }^{1}$, \\ J. Balboa ${ }^{1}$, M. Cuello ${ }^{1}$, O. Cabrera ${ }^{1}$, M. Lastre ${ }^{1}$ and V.E.J.C. Schijns ${ }^{3}$ \\ ${ }^{1}$ Immunology Department, Research Vice Presidency, Finlay Institute, Havana City, Cuba \\ ${ }^{2}$ Immunotoxicology Laboratory, Toxicology and Biomedicine Centre, Santiago de Cuba, Cuba \\ ${ }^{3}$ Department of Cell Biology and Immunology, Wageningen University, Wageningen, The Netherlands
}

\begin{abstract}
Adjuvants have been considered for a long time to be an accessory and empirical component of vaccine formulations. However, accumulating evidence of their crucial role in initiating and directing the immune response has increased our awareness of the importance of adjuvant research in the past decade. Nevertheless, the importance of adjuvants still is not fully realized by many researchers working in the vaccine field, who are involved mostly in the search for better target antigens. The choice of a proper adjuvant can be determinant for obtaining the best results for a given vaccine candidate, but it is restricted due to intellectual property and know-how issues. Consequently, in most cases the selected adjuvant continues to be the aluminum salt, which has a record of safety, but predominantly constitutes a delivery system (DS). Ideally, new strategies should combine immune potentiators (IP) and DS by mixing both compounds or by obtaining structures that contain both IP and DS. In addition, the term immune polarizer has been introduced as an essential concept in the vaccine design strategies. Here, we review the theme, with emphasis on the discussion of the few licensed new adjuvants, the need for safe mucosal adjuvants and the adjuvant/immunopotentiating activity of conjugation. A summary of toxicology and regulatory issues will also be discussed, and the Finlay Adjuvant Platform is briefly summarized.
\end{abstract}

Key words: Human vaccines; Adjuvants; Finlay adjuvants; AFPL $1^{\mathrm{TM}} ; \mathrm{AFCo} 1$

\section{Introduction}

Adjuvants are molecules, compounds or macromolecular complexes that boost the potency and longevity of the specific immune response to antigens (1). Most adjuvant research has been an empirical process until recently, when an increased understanding of the mechanisms of immune response induction and the essential bridging of innate and adaptive immune responses has paved the way to a more rational adjuvant design. These breakthrough advances involve a deeper knowledge of how the innate immune system acts to recognize pathogens and damage-associated signals and how this recognition by different receptors may ultimately influence the potency and polarization of the immune responses.

A functional classification of adjuvants was elaborated by Schijns (2), categorizing these molecules as facilitators of signal 1 (delivery of antigen) or signal 2 (i.e., appropri- ate immunostimulation; costimulation). Later, Valenti and O'Hagan (3) divided adjuvants into immune potentiators (IP) and delivery systems (DS). An additional category of adjuvants may be recognized as immune polarizing (IPz) components that are capable of shifting the immune response in the desired direction required for protection (4), also referred to as signal 3 in the classification of Schijns (2). This last concept is extremely important: as long as the required protective response is known, it is possible to rationally select the appropriate adjuvant to facilitate it.

In other words, vaccine adjuvants are capable of enhancing, sustaining and directing the immunogenicity of antigens, thereby effectively modulating appropriate immune responses, reducing the amount of antigen and/ or number of required immunizations, and improving the efficacy of vaccines, which is of increased relevance for

Correspondence: O. Pérez, Immunology Department, Research Vice Presidency, Finlay Institute, P.O. Box 16017, Havana City, Cuba. E-mails: oliverp@Finlay.edu.cu or virgil.schijns@wur.nl

Received November 2, 2011. Accepted April 13, 2012. Available online April 27, 2012. Published August 3, 2012. 
vaccination strategies aimed at newborns, elderly, or immune-compromised individuals (5). It is important to stress, however, that they need to cause minimal toxicity and avoid long-lasting immune effects on their own in order to be translated to clinical practice.

One major current question in the vaccinology field is whether adjuvants are additional or essential components of vaccine formulations. For a long time, only live or attenuated organisms and vaccines containing aluminum salts (alum) have proven successful. However, vaccine history has traditionally focused on the identification of particular antigens and more restrictedly single epitopes to induce protection. Research on vaccine adjuvants has so far received little attention as an independent scientific discipline from most of the main research-funding agencies and policy makers (6), although some pharmaceutical companies have made adjuvant research a priority. Today we are in the golden age of adjuvant research as a result of two factors. First, vaccinology per se (either prophylactic or therapeutic) is in its golden age, and second, our knowledge of immunology has dramatically improved, especially regarding the recently appreciated role of innate immunity as an essential part of the immune system, indispensable to bridge towards and amplify adaptive immunity. In this review, we aim to discuss the role of adjuvants in vaccine formulations and how they are being increasingly explored to rationally design more efficient vaccines.

\section{Learning from current vaccines}

There are currently 90 registered prophylactic vaccines produced by different companies against 31 bacterial or viral pathogens, but no vaccines against protozoan or helminths. This survey does not include: 1) vaccines against the same disease applied by different routes (like polio); 2) vaccines that cover different serogroups (like serogroup $B$ and $C$ of VAMENGOC-BC ${ }^{\mathrm{TM}}$, conjugated $\mathrm{A}, \mathrm{C}, \mathrm{Y}$, and $W_{135}$, and pneumococcal serogroups), and 3) mixed and combined vaccines. Interestingly, there are several vaccines against the same diseases: the differences in formulations are the results of the search for intellectual properties.

\section{Live attenuated and inactivated plus adjuvant (non-alum salt) vaccines}

Table 1 lists the live-attenuated and inactivated current vaccines, which are available. presented together because they are considered to be non-adjuvanted, but contain several immunostimulants with adjuvant behavior, which are intrinsic to the organisms they are made of. Sixteen vaccines contain most attributes of live pathogens and induce a potent/efficient immune response and protection, being considered as the most efficient vaccines developed so far. Consequently, the poly-antigens and -adjuvants present in these vaccines allow the induction of potent immune responses without the requirement of additional adjuvants. Nevertheless, some of them, like whole cell pertussis, hepatitis A, and split flu virus, are also formulated with other adjuvants.

Natural immunostimulants present in live-attenuated or inactivated vaccines exert adjuvant activity or function as antigens. Components with adjuvant properties are usually more than one and are expressed in multimeric form. They depend on the microorganism from which they are coming,

Table 1. Live attenuated and inactivated plus inherent adjuvant vaccines.

\begin{tabular}{|c|c|c|c|c|}
\hline Adjuvant & Vaccine & Route & Name & Manufacturer \\
\hline \multirow[t]{2}{*}{ Live } & \multirow[t]{2}{*}{ BCG } & \multirow[t]{2}{*}{$i d$} & TICE BCG ${ }^{\mathrm{TM}}$ & Organon Teknika \\
\hline & & & Mycobax $^{\mathrm{TM}}$ & Sanofi Pasteur \\
\hline Live & Typhoid Ty21a & oral & Vivotif $^{\mathrm{TM}}$ & Berna Biotech \\
\hline Live & $\mathrm{Va}$ & $s c$ & Varivax $^{\mathrm{TM}}$ & Merck \\
\hline Live & Zoster & $s c$ & Zostavax $^{\mathrm{TM}}$ & Merck \\
\hline Live & Rubella & $s c$ & Meruvax $^{\mathrm{TM}}$ II & Merck \\
\hline \multirow[t]{2}{*}{ Live } & \multirow[t]{2}{*}{ Rotavirus } & \multirow[t]{2}{*}{ oral } & Rotarix $^{\mathrm{TM}}$ & GSK \\
\hline & & & RotaTeq $^{\mathrm{TM}}$ & Merck \\
\hline \multirow[t]{2}{*}{ Live } & \multirow[t]{2}{*}{ Smallpox } & \multirow[t]{2}{*}{$p c$} & ACAM $2000^{\mathrm{TM}}$ & Acambis \\
\hline & & & Dryvax $^{\mathrm{TM}}$ & Wyeth \\
\hline Live & Influenza & in & FluMist $^{\mathrm{TM}}$ & Medlmmune \\
\hline Live & $\mathrm{Me}$ & $s c$ & Attenuvax $^{\mathrm{TM}}$ & Merck \\
\hline Live & $\mathrm{Mu}$ & $s c$ & Mumpsvax $^{\mathrm{TM}}$ & Merck \\
\hline Live & $\mathrm{Me} / \mathrm{Mu}$ & $s c$ & $M-M-V a x^{T M}$ & Merck (NA) \\
\hline Live & $\mathrm{Me} / \mathrm{Ru}$ & $s c$ & MoRu-Viraten ${ }^{\mathrm{TM}}$ & Crucell \\
\hline Live & $\mathrm{Me} / \mathrm{Mu} / \mathrm{Ru}$ & $s c$ & $M-M-R^{T M}$ II & Merck \\
\hline Live & $\mathrm{Me} / \mathrm{Mu} / \mathrm{Ru} / \mathrm{Va}$ & $s c$ & ProQuad $^{\mathrm{TM}}$ & Merck \\
\hline Live & Yellow fever & $s c$ & YF-Vax ${ }^{\mathrm{TM}}$ & Sanofi Pasteur \\
\hline Live & Poliomyelitis & oral & NTM & Aventis-Pasteur, GSK, etc. \\
\hline \multirow{6}{*}{ Inactivated } & \multirow[t]{6}{*}{ Influenza } & \multirow[t]{6}{*}{$i m$} & Afluria $^{\mathrm{TM}}$ & CSL Limited \\
\hline & & & FluLaval $^{\mathrm{TM}}$ & GSK \\
\hline & & & Fluarix $^{\mathrm{TM}}$ & GSK \\
\hline & & & Fluvirin $^{\mathrm{TM}}$ & Novartis \\
\hline & & & Fluzone $^{\mathrm{TM}}$ & Sanofi Pasteur \\
\hline & & & Influvac ${ }^{\mathrm{TM}}$ & Solvay \\
\hline \multirow[t]{2}{*}{ Inactivated } & \multirow[t]{2}{*}{ Rabies } & \multirow[t]{2}{*}{$i m$} & Imovax $^{\mathrm{TM}}$ & Sanofi Pasteur \\
\hline & & & RabAvert $^{\mathrm{TM}}$ & Novartis \\
\hline
\end{tabular}

$i d=$ intradermal; $s c=$ subcutaneous; $p c=$ percutaneous; in = intranasal, $i m=$ intramuscular; $\mathrm{Va}=$ varicella; $\mathrm{Me}=$ measles; $\mathrm{Mu}=$ mumps; $\mathrm{Ru}=$ rubella; $\mathrm{NA}=$ not 
i.e., Gram-negative bacteria contain lipopolysaccharide (LPS), porins, flagellin, and bacterial DNA as the main pathogen-associated molecular pattern (PAMP), but viruses contain mainly dsRNA or ssRNA as main PAMP (reviewed in Ref. 7). Antigens are often also multimeric, and with the aid of the associated adjuvants' activity guarantee a broader spectrum of immune response, thereby resulting in a more efficient avoidance of pathogen-escape mechanisms.

The live-attenuated pathogens naturally contain several IP, DS, and IPz agents that induce strong stimulation of the innate immune response and favor adaptive immune responses with the desired pattern. In addition, the in vivo persistence and multiplication of live organisms elicits prolonged immune stimulation, often after a single dose.

However, due to their strong potency, these vaccines induce important adverse reactions, which can range from simple headache to encephalitis (mumps-measles-rubella), intussusception (rotavirus), vaccine-associated diseases (polio) and even death (smallpox) (8). The inactivation or attenuation processes in general tend to decrease the proportion of the most harmful components reducing the reactogenicity, but this decrease is not enough to eliminate it completely. Hence, it is very unlikely that new vaccines in this format would be approved today by regulatory bodies (9).

Note that three live vaccines are oral (two against rotavirus, produced by different companies), and only one is nasal. Two other vaccines consist of inactivated organisms and contain several attributes of the source pathogens, but fail to multiply. Therefore, they might become less effective than live-attenuated vaccines, but are also less reactogenic. Typical reactions range from nausea to anaphylactic reactions and neurological complications (6).

\section{Conjugated vaccines}

Conjugation has been a great contribution of chemistry to the field of vaccinology. This technique has been used to help induce a long-lived, thymus-dependent (TD) $s c=$ subcutaneous. response against thymus-independent $(\mathrm{TI})$ antigens such as polysaccharides. A list of current conjugated vaccines is presented in Table 2.

Antigens can be classified as TD (most proteins) or TI. The $\mathrm{TI}$ responses are divided into types 1 and 2 . The TI-1 inducing LPS present lymphocyte-B mitogenic activity at high doses, and a specific response at low doses. They stimulate immature and mature $B$ cells in newborn, and IgM antibodies in CBA/N (xid) mice. In contrast, the TI-2 like polysaccharides have repetitive epitopes, are resistant to degradation and activate the complement system. They only stimulate mature $B$ cells, and this stimulation does not occur in newborn or xid mice (10). They induce IgM and IgG antibody specific responses (of the lgG3 subclass in mice, and IgG2 in humans) (11,12). T cell-independent antibody responses do not induce memory; consequently, they induce short-lived protection.

In vaccinology, the covalent conjugation of a TI-2 polysaccharide to a carrier (which is, most of the time, of protein origin) transforms it in a TD antigen. The carrier adds mainly Thelper (Th) epitopes, solving most problems associated with TI-2 antigens for children under 2 years of

Table 2. Conjugated (including conjugation plus alum and conjugation plus built-in immunopotentiating components/antigens) and non-adjuvanted vaccines.

\begin{tabular}{|c|c|c|c|c|c|}
\hline & Adjuvant & Vaccine & Route & Name & Manufacturer \\
\hline \multirow[t]{3}{*}{1} & OMP NmB & $\mathrm{Hib}$ & $i m$ & PedvaxHIB ${ }^{\mathrm{TM}}$ & Merck \\
\hline & TT & & & ActHIB ${ }^{\mathrm{TM}}$ & Sanofi Pasteur \\
\hline & TT & & & Quimi-Hib $^{\mathrm{TM}}$ & Heberbiotec \\
\hline 2 & DT & Poly A, C, Y, W 135 & $i m$ & Menactra $^{\mathrm{TM}}$ & Sanofi Pasteur \\
\hline 3 & OMP NmB + Alum & $\mathrm{Hib}+\mathrm{HB}$ & $i m$ & Comvax $^{\mathrm{TM}}$ & Merck \\
\hline 4 & $\mathrm{CRM}_{197}+$ Alum & Pneumococcal 7-valent & im & Prevnar $^{\mathrm{TM}}$ & Wyeth \\
\hline \multirow[t]{3}{*}{5} & $\mathrm{CRM}_{197}+\mathrm{Al}_{4}\left(\mathrm{OHPO}_{4}\right)_{3}$ & Poly C & $i m$ & Meningitec $^{\mathrm{TM}}$ & Wyeth \\
\hline & $\mathrm{CRM}_{197}+\mathrm{Al}(\mathrm{OH})_{3}$ & & & Menjugate $^{\mathrm{TM}}$ & Novartis \\
\hline & $\mathrm{TT}+\mathrm{Al}(\mathrm{OH})_{3}$ & & & NeisVac-C ${ }^{\mathrm{TM}}$ & Baxter \\
\hline 6 & TT + Alum + IPV & $\mathrm{DaPT}+\mathrm{PV}+\mathrm{Hib}$ & im & Pentacel $^{\mathrm{TM}}$ & Sanofi Pasteur \\
\hline 7 & $\mathrm{TT}+$ Alum + IPV & $\mathrm{DaPT}+\mathrm{HB}+\mathrm{PV}+\mathrm{Hib}$ & $i m$ & Infanrix hexa ${ }^{\mathrm{TM}}$ & GSK \\
\hline \multirow[t]{3}{*}{8} & - & Poly A, C & $\mathrm{im} / \mathrm{sc}$ & Mengivac $^{\mathrm{TM}}$ & Sanofi Pasteur \\
\hline & & & & Vax-MEN-AC ${ }^{\mathrm{TM}}$ & Finlay \\
\hline & & & & $A C \operatorname{vax}^{\mathrm{TM}}$ & GSK \\
\hline \multirow[t]{2}{*}{9} & - & Poly A, C, $\mathrm{W}_{135}, \mathrm{Y}$ & $i m$ & Menomune $^{\mathrm{TM}}$ & Sanofi Pasteur \\
\hline & & & & ACWY $\operatorname{vax}^{\mathrm{TM}}$ & GSK \\
\hline \multirow[t]{3}{*}{10} & - & Typhoid Vi & $\mathrm{im} / \mathrm{sc}$ & TYPHIM Vi ${ }^{\mathrm{TM}}$ & Sanofi Pasteur \\
\hline & & & & TyTherix $^{\mathrm{TM}}$ & GSK \\
\hline & & & & vax-TyVi ${ }^{\mathrm{TM}}$ & Finlay \\
\hline 11 & - & Pnemococcus 23-valent & $\mathrm{im} / \mathrm{sc}$ & Pneumovax ${ }^{\mathrm{TM}}$ & Merck \\
\hline
\end{tabular}

OMP NmB = outer membrane protein from Neisseria meningitidis serogroup B; TT = tetanus toxoid; $\mathrm{DT}=$ diphtheria toxoid; alum $=\mathrm{Al}(\mathrm{OHPO})_{4} \mathrm{SO}, \mathrm{Al}(\mathrm{OH})_{3}, \mathrm{Al}_{4}\left(\mathrm{OHPO}_{4}\right)_{3} ; \mathrm{CRM}_{197}=$ nontoxic diphtheria toxin mutant; IPV = inactivated poliovirus; Hib = Haemophilus influenzae b; Poly A, C, Y, $\mathrm{W}_{135}$ = polysaccharides from Neisseria meningitidis serogroups $\mathrm{A}, \mathrm{C}, \mathrm{Y}$, or $\mathrm{W}_{135}$, respectively; $\mathrm{HB}$ = hepatitis $\mathrm{B} ; \mathrm{DaPT}=$ diphtheria, acellular pertussis, tetanus; $\mathrm{PV}=$ poliovirus; $i m$ = intramuscular; 
age (13). Neonates can mount effective antigen-specific $\mathrm{T}$-cell responses, even though CD4 T-cell responses are often slower to develop, less readily sustained and in most cases more easily biased towards a T helper 2 (Th2) type of response, most probably because of the decreased efficiency of neonatal dendritic cells (DCs) to establish Th1 CD4 T-cell responses (14). Neonates and infants may require multiple immunizations to achieve or sustain titers comparable to those in older individuals (15).

Conjugated vaccines provide $\mathrm{T}$ cell help by using a carrierpreferably covalently linked to saccharides, thus we consider this to be a form of adjuvation. The most prevalent carriers include: tetanus toxoid, CRM197 (nontoxic diphtheria toxin mutant), and outer membrane proteins from Neisseria meningitidis serogroup $\mathrm{B}$. One forthcoming problem is the repetitive use (including that all are vaccine antigens) of the few currently used carriers that might become immune dominant, resulting in vaccine failure.

\section{Alum-based vaccines}

Formulations with alum have a long record of safety, mainly because alum entraps the antigens in depot areas and is slowly liberated (a few hours may be sufficient) or taken up by phagocytosis. Table 3 lists current vaccines that employ alum as an adjuvant. There are several caveats related to the use of alum: alum includes three different compounds (aluminum hydroxide, aluminum hydroxyphosphate, and aluminum hydroxy-phosphate-sulfate), it may include self-inactivated antigens with inherent adjuvant behavior, and finally, other adjuvants have been included in the alum formulation. It is important to note that the accidental freezing of alum-containing vaccines destroys the formulation and impairs the efficacy of the vaccine. This is estimated to occur in up to $70 \%$ of available vaccines in low income countries (16). Finally, alum can induce granulomas at the injection site, a concern for vaccines requiring frequent boosts (17).

The mechanisms underlying the adjuvant properties of alum are still not completely understood. Alum induces particulate and depot formation, inflammation, recruitment of antigen-presenting cells, increased major histocompatibility complex (MHC) class II expression and antigen presentation, T-cell activation and differentiation, and boosts the humoral immunity by providing Th2 cell help to follicular B cells (18). This involves an increase in uric acid levels (19) and nucleotide oligomerization domain (NOD)-like receptor family, NALP3-dependent caspase-1 activation and interleukin (IL)-1 $\beta$ secretion (20). Interestingly, alum does not trigger classical DC maturation in vitro (21).

Alum activity has been associated with the secretion of uric acid (19). This concept is strongly challenged by earlier data showing that uric acid crystals augment cytotoxic T lymphocyte (CTL) responses to co-injected antigen, which, by contrast, was not observed for alum in the same animal experiments (22). Hence, uric acid polarizes the immune response towards a CTL reaction, which is Th1 associated, while a Th2-type response is the hallmark of alum adjuvanted vaccines. In fact, the lack of proper CTL priming by alum may represent its major deficiency as a vaccine adjuvant. Nevertheless, a recent report has demonstrated the capacity of alum to help in the generation of antigen-specific cytotoxic/interferon- $\gamma$ producing effector-memory CD8 ${ }^{+} \mathrm{T}$ cells, but this has occurred only in the presence of an additional adjuvant, monophosphoryl lipid A (MPL) (23).

Alum has been shown to be able to activate the NALP3 inflammasome in human peripheral blood cells (24) and in primary peritoneal macrophages of mice (20). However, such activation is dependent on cell priming with LPS. Remarkably, in NALP3-deficient mice, only a partial reduction of alum-induced antigen-specific antibody formation was observed using ovalbumin (OVA) or human serum albumin as antigens $(20,24)$. NALP3-deficient mice are able to mount normal antibody responses when immunized with antigen in alum adjuvant (25). Furthermore, of particular importance is a recent study demonstrating that mice lacking myeloid differentiation primary-response gene 88 (MyD88), and therefore unable to respond to Toll-like receptor (TLR) signals or to IL-1 $\beta$ and IL-18 (26), are still capable of generating normal antibody responses when stimulated by repository vaccine adjuvants including aluminum hydroxide and Freund's incomplete and complete adjuvant (27). Also humoral immune responses such as OVA-specific immunoglobulin (Ig)G1 and IgE production (the hallmark of alum's adjuvant effects) remained unaffected in IL-18-deficient mice (28). Taken together, these data do not support the recently proposed NALP3 pathway (20), nor the uric acid concept (19) for alum adjuvant activity. In addition, there is no evidence for IL-18 or IL-1 $\beta$ dependence.

Recent reports have shown possible NALP3-independent mechanisms that may account for the adjuvant behavior of alum. Alum crystals have been shown to be capable of interacting with lipids in the plasma membrane DCs, including cholesterol and sphingomyelin, inducing lipid sorting that leads to cell activation through a Syk- and PI3K-dependent mechanism. In this system, alum-treated DCs up-regulated intercellular adhesion molecule-1 (ICAM1) increasing their interaction with $C D 4^{+} \mathrm{T}$ lymphocytes (29). On the other hand, the moderate cytotoxicity of alum may lead to a limited but functionally important release of molecules that act as damage-associated molecular patterns (DAMPs), among them host DNA, which has the property of stimulating humoral responses through the Irf3 pathway (30).

Alum is not always satisfactory as an adjuvant $(31,32)$. New potent adjuvants are particularly required to: 1 ) induce immunity with long-term protection and immunological memory; 2) overcome weak immunity during the neonatal period, during immune-suppression or immune-senes- 
cence; 3 ) overcome the escape mechanism of invaders or tumors; 4) induce a broader immune response against serogroups, serotypes, immunotypes, or other subgroups of the same species; 5) stimulate strong T-cell responses, including $\mathrm{CTL}$, and 6 ) reduce the schedule of immunization (fewer doses, less antigen concentration).

\section{Non-adjuvanted vaccines}

There are only few non-adjuvanted vaccines (Table 2). These include polysaccharide-based vaccines, which are not suitable for infants less than 2 years of age, when some of these diseases are important.

Table 3. Alum-based vaccines (alum, alum plus self-inactivated, and alum plus other adjuvants).

\begin{tabular}{|c|c|c|c|c|c|}
\hline & Adjuvant & Vaccine & Route & Name & Manufacturer \\
\hline 1 & Alum & Anthrax & im & Biothrax $^{\mathrm{TM}}$ & Emergent bioDefense \\
\hline \multirow[t]{2}{*}{2} & Alum & Tetanus & im & $\operatorname{vax}-\mathrm{TET}^{\mathrm{TM}}$ & Finlay \\
\hline & & & & NTM & Sanofi Pasteur \\
\hline \multirow[t]{4}{*}{3} & Alum & DT, adult & im & TENIVAC $^{\mathrm{TM}}$ & Sanofi Pasteur \\
\hline & & & & DECAVAC ${ }^{\mathrm{TM}}$ & Sanofi Pasteur \\
\hline & & & & VA-DIFTET $^{\mathrm{TM}}$ & Finlay \\
\hline & & & & NTM & Massachusetts PH Biologic Lab \\
\hline 4 & Alum & $\mathrm{dT}$, pediatric & im & VA-DIFTET ${ }^{\mathrm{TM}}$ & Finlay \\
\hline \multirow[t]{5}{*}{5} & Alum & $\mathrm{DaPT}$ & im & Tripedia $^{\mathrm{TM}}$ & Sanofi Pasteur \\
\hline & & & & Infanrix ${ }^{\mathrm{TM}}$ & GSK \\
\hline & & & & Boostrix $^{T M}$ & GSK \\
\hline & & & & DAPTACEL ${ }^{\mathrm{TM}}$ & Sanofi Pasteur \\
\hline & & & & Adacel $^{\mathrm{TM}}$ & Sanofi Pasteur \\
\hline 8 & Alum & $\mathrm{DTaP}+\mathrm{HB}+\mathrm{Hib}$ & im & Quinvaxem $^{\mathrm{TM}}$ & Berna Biotech \\
\hline 9 & Alum, wP & $\mathrm{DT}+\mathrm{wP}+\mathrm{HB}$ & im & Trivac-HB $^{\mathrm{TM}}$ & Heberbiotec \\
\hline 10 & Alum, wP & $\mathrm{DTwP}+\mathrm{HB}+\mathrm{Hib}$ & im & Heberpenta $^{\mathrm{TM}}$ & Heberbiotec \\
\hline \multirow[t]{2}{*}{11} & Alum, IPV & Poliomyelitis & $\mathrm{im} / \mathrm{sc}$ & Poliovax ${ }^{\mathrm{TM}}$ & Sanofi Pasteur NA \\
\hline & & & & $\mid \mathrm{pol}^{\mathrm{TM}}$ & Sanofi Pasteur \\
\hline 12 & Alum, wL & Leptospira & im & Vax-SPIRAL $^{\mathrm{TM}}$ & Finlay \\
\hline 13 & Alum, wP & DTwP & im & NTM & Finlay \\
\hline 14 & Alum, IPV & $\mathrm{DaPT}+\mathrm{PV}$ & im & Kinrix $^{T M}$ & GSK \\
\hline 15 & Alum, IPV & $\mathrm{DaPT}+\mathrm{HB}+\mathrm{PV}$ & $i m$ & Pediarix $^{\mathrm{TM}}$ & GSK \\
\hline 16 & Alum, IHA & $\mathrm{HA}$ & im & Havrix $^{\mathrm{TM}}$ & GSK \\
\hline \multirow[t]{2}{*}{17} & Alum, IHA & $\mathrm{HA}+\mathrm{HB}$ & im & $V_{A Q T A}{ }^{T M}$ & Merck \\
\hline & & & & Twinrix $^{T M}$ & GSK \\
\hline 18 & Alum, IJE & Japanese encephalitis & im & Ixiaro $^{\mathrm{TM}}$ & Intercell Biomedical \\
\hline 19 & Alum, IR & Rabies & im & $\mathrm{JE}-\mathrm{Vax}^{\mathrm{TM}}$ & Res Fund Microbial Dis Osaka Univ \\
\hline 20 & Alum, AFPL $1^{\mathrm{TM}}$ & Meningococcus $\mathrm{BC}$ & im & VA-MENGOC-BC ${ }^{\mathrm{TM}}$ & Finlay \\
\hline 21 & Alum, MPL & $\mathrm{HB}$ & im & Fendrix $^{\mathrm{TM}}$ & GSK \\
\hline 22 & Alum, MPL, VLP & PV & im & Cervarix $^{\mathrm{TM}}$ & GSK \\
\hline \multirow[t]{5}{*}{23} & Alum, VLP & $\mathrm{HB}$ & im & Heberbiovac-HB ${ }^{\text {TM }}$ & Heberbiotec \\
\hline & & & & Recombivax $\mathrm{HB}^{\mathrm{TM}}$ & Merck \\
\hline & & & & Engerix- $\mathrm{B}^{\mathrm{TM}}$ & GSK \\
\hline & & & & Hepavax-Gene ${ }^{\mathrm{TM}}$ & Berna Biotech \\
\hline & & & & Shanvac- $\mathrm{B}^{\mathrm{TM}}$ & Shantha Biotech \\
\hline 24 & Alum, VLP & PV & im & Gardasil $^{\mathrm{TM}}$ & Merck \\
\hline
\end{tabular}

Alum = Al $\left(\mathrm{OHPO}_{4}\right) \mathrm{SO}, \mathrm{Al}(\mathrm{OH})_{3}, \mathrm{Al}_{4}\left(\mathrm{OHPO}_{4}\right)_{3} ; \mathrm{D}=$ diphtheria; $\mathrm{T}$ = tetanus; $\mathrm{aP}$ = acellular pertussis; $\mathrm{wP}=$ whole pertussis; $\mathrm{wL}=$ whole Leptospira; IPV = inactivated poliovirus; IHA = inactivated hepatitis A; IJE = inactivated Japanese encephalitis; IR = inactivated rabies; Hib = Haemophilus influenzae b; HB = hepatitis B; L = Leptospira; PV = poliovirus; $\mathrm{AFPL} 1^{\mathrm{TM}}=$ Finlay adjuvant proteoliposome $1 ; \mathrm{MPL}=$ monophosphoryl lipid A; VLP = virus-like particle; im = intramuscular; $s c=$ subcutaneous; NTM = no trademark. 
Table 4. Newly licensed adjuvants.

\begin{tabular}{|c|c|c|c|c|c|c|}
\hline & Adjuvant & IP & DS & $\mathrm{IPz}$ & Vaccine & Manufacturer \\
\hline 1 & $\mathrm{Al}(\mathrm{OH})_{3}$ & I Influenza & $x$ & Th2 & Several & See Table 3 \\
\hline 2 & $\mathrm{Al}_{4}\left(\mathrm{OHPO}_{4}\right)_{3}$ & I Influenza & $x$ & Th2 & Several & See Table 3 \\
\hline 3 & $\mathrm{Al}\left(\mathrm{OHPO}_{4}\right) \mathrm{SO}$ & HPV & $x$ & $?$ & Gardasil $^{\mathrm{TM}}$ & Merck \\
\hline 4 & $\mathrm{Ca}_{3}\left(\mathrm{PO}_{4}\right)_{2}$ & DTP & $x$ & Th2 & Several & Pasteur Institute \\
\hline 5 & MF59 & I Influenza & $\mathrm{O} / \mathrm{W}$ & Th2 & $\begin{array}{l}\text { Afluov }^{\mathrm{TM}}(\mathrm{H} 5 \mathrm{~N} 3) \\
\text { Focetria }^{\mathrm{TM}}(\mathrm{H} 5 \mathrm{~N} 1)\end{array}$ & Novartis \\
\hline 6 & MPL & MPL & - & Th1 & Allergy & Allergy Therapeutics \\
\hline 7 & AS03 & I Influenza & $\mathrm{O} / \mathrm{W}$ & $?$ & Prepandrix $^{\mathrm{TM}}(\mathrm{H} 5 \mathrm{~N} 1)$ & GSK \\
\hline 8 & AS04 & MPL & Alum VLP & Th1 & Cervarix $^{\mathrm{TM}}$ & GSK \\
\hline 9 & RC529 & MPL synthetic & Alum & Th1 & Supervax $^{\mathrm{TM}}$ & Berna Biotech \\
\hline 10 & Virosome (VLP, IRIV) & $\mathrm{IHA}$ & Lipid & Th1 & Epaxal $^{\mathrm{TM}}$ & Berna Biotech \\
\hline 11 & $\begin{array}{l}\text { Virosome (VLP, IRIV) } \\
\text { AFPL1 }^{\text {TM }}\end{array}$ & $\begin{array}{l}\text { I Influenza } \\
\text { Inserted LPS, porins, bacterial DNA }\end{array}$ & $\begin{array}{l}\text { Lipid } \\
\text { Lipid }\end{array}$ & $\begin{array}{l}\text { Th1 } \\
\text { Th1 CTL }\end{array}$ & $\begin{array}{l}\text { Inflexal }{ }^{\mathrm{TM}} \mathrm{V} \\
\text { VA-MENGOC-BC }^{\mathrm{TM}}\end{array}$ & $\begin{array}{l}\text { Berna Biotech } \\
\text { Finlay }\end{array}$ \\
\hline
\end{tabular}

IP = immune potentiators; DS = delivery system; Ipz = immune polarizer; I = inactivated; Th = T helper lymphocyte; HPV = human papillomavirus; DTP = diphtheria, tetanus, pertussis; $\mathrm{O} / \mathrm{W}=$ oil in water; $\mathrm{MPL}^{\mathrm{TM}}=$ monophosphoryl lipid $\mathrm{A} ; \mathrm{AS} 03=$ adjuvant system containing a $10 \%$ oil-in-water emulsion-based adjuvant; $\mathrm{ASO} 4$ = aqueous formulation of MPL and alum; $\operatorname{alum}=\mathrm{Al}(\mathrm{OHPO}) \mathrm{SO}, \mathrm{Al}(\mathrm{OH})_{3}$, $\mathrm{Al}_{4}\left(\mathrm{OHPO}_{4}\right)_{3} ; \mathrm{VLP}=$ virus-like particle; IRIV = immunostimulating reconstituted influenza virosomes; HA = hepatitis $\mathrm{A} ; \mathrm{AFPL} 1^{\mathrm{TM}}=\mathrm{Fin}-$ lay adjuvant proteoliposome 1; LPS = lipopolysaccharide; CTL = cytotoxic T lymphocyte.

\section{Newly licensed adjuvants}

So far, only alum and AS04 adjuvants are licensed as part of human vaccines in the US. Other proposed adjuvants are licensed mainly in Europe. Vaccines using newly licensed adjuvants are listed in Table 4. MPL was the first IP capable of activating T-cell effector responses to be used in a licensed vaccine. MPL is a nontoxic derivative of the LPS of Salmonella minnesota (33). On the other hand, the Neisseria meningitidis B proteoliposome adjuvant AFPL $1^{\mathrm{TM}}$, which contains inserted natural LPS, has been used in the meningococcal $B C$ vaccine (34), and is the most extensively used LPS-derived adjuvant, with more than 55 million doses given so far (27 million of vaccinees) (35). MPL alone is only used in allergy immunotherapy (36) but in combination with other adjuvants (alum, QS21, O/W, RC529) it is used in several vaccines. MF59 ${ }^{\mathrm{TM}}$ consists of an oil (squalene)-in-water nano-emulsion composed of $<250$ $\mathrm{nm}$ droplets (37), and is used in Europe against influenza (38). AS03 is an adjuvant system containing a $10 \%$ oil-inwater emulsion-based adjuvant, and was approved for use in influenza (39). AS04 is an aqueous formulation of MPL and alum (40). Virosomes are liposomes that have proteins or lipids from the envelope of a virus. These could be virallike particles (VLP) or reconstituted virosomes (IRIV). The VLPs are self-assembling nano-particles composed of one or more viral proteins and viral lipids. The IRIV is a virosome constituted by phospholipids, influenza hemagglutinin, and a selected target antigen (41). It is expected that within the next 5-year period, in addition to the TLR4 agonists MPL and AFPL1 (which is also an agonist of TLR2 and TLR9), other TLR-based adjuvants will become components of vaccines approved for human use (6).

\section{Mucosal adjuvanted vaccines}

Assuming that the protection induced by recovery from natural infection is in general better than that induced by vaccination, and given that the invasion or establishment of the vast majority of pathogens occurs in the mucosal tissues, it is reasonable to consider that vaccines may work better when applied via mucosal routes. More than $90 \%$ of infectious agents enter or establish themselves in the 400 $\mathrm{m}^{2}$ of mucosa where millions of commensal species live. However, the majority of existing vaccines (both prophylactic and therapeutic) are given via the parenteral route, which fails to induce strong mucosal immune responses.

Presently, vaccine researchers, vaccine companies, and founder agencies emphasize that future vaccines need to be developed for alternative routes of immunization, particularly the important but less exploited mucosal route. Mucosal immunization offers a number of potential advantages over the parenteral vaccination, including reduced risk of reactogenicity/toxicity and of transmission of infectious agents (for example through contaminated needles carrying human immune-deficiency and hepatitis $B$ viruses), as well as enhanced patient compliance due to ease of administration and minor invasiveness. The mucosal route also allows the induction of both mucosal and systemic immune responses, a feature that other routes do not exhibit.

The two main mechanisms of immune protection at 
mucosal sites are the production of secretory $\lg \mathrm{A}(\mathrm{S} \lg \mathrm{A})$ and the induction of CTL. SlgAis the main immune-specific element involved in mucosal protection. Nearly $80 \%$ of all immunocytes are in the mucosa and $70 \%$ of them are $C D 8^{+} \mathrm{T}$ cells. However, our understanding of mucosal immunity and of how to develop mucosal vaccines remains largely incomplete (6).

Even though $\lg \mathrm{A}$ is produced abundantly ( $\sim 3 \mathrm{~g}$ per day) there are important questions concerning this antibody class. The first is how to induce preferably antibodies of the IgA2 subclass, which are more resistant to protease digestion promoted by several nasopharyngeal bacterial infections. The second is how the organism can produce this huge amount of $\lg \mathrm{A}$ in an environment that is rich in regulatory $T$ cells. The third question is how the balance between specific and nonspecific or cross-reactogenic $\lg \mathrm{A}$ is established.

The induction of potent mucosal immunity by mucosal administration of protein antigens has often proven to be difficult, and the recovery and functional testing of antibodies or T cells from mucosal sites are labor intensive and technically challenging (42). The mucosal route, particularly the oral one, is more often involved in the induction of tolerance, mainly to food (43). The epithelial mucosa is more fragile than other tissues, and needs to be protected from inflammation (reviewed in Ref. 44). Nevertheless, both probiotic (commensal) and dangerous microorganisms somehow elicit some kind of mucosal immune response. Commensal organisms (e.g., Bacteroides thetaiotaomicron) not only induce mucosal responses required to control them but also modulate many genes involved in the intestinal barrier function and in nutrient absorption (45). The ability to contain the microbiota in this region is dependent on pattern recognition receptors (PRRs), since a deficiency in TLR signaling results in the increased uptake of bacteria and consequently of their recovery in the spleens of mice (46). The importance of NOD signaling in the mucosa has been well established (47). NOD2 deficiency results in the abnormal development and function of Peyer's patches in mice (48), which become more susceptible to oral infection with Listeria monocytogenes (49). NOD1-deficient mice are also highly susceptible to infection with Helicobacter pylori (50). Regulatory $\mathrm{T}$ cells in the intestine maintain immunological tolerance to self-antigens and have an important role in suppressing damaging inflammatory responses (48). However, DNA from commensal bacteria limits the induction of inducible regulatory $T$ cells through TLR9 signaling (51).

The microbiota has an essential role in promoting the development of IgA-producing plasma cells and there is evidence that this enhancing effect is driven by specific bacterial species (44). TLR5 has been demonstrated to promote $\lg \mathrm{A}^{+}$ B-cell differentiation. A population of TLR5 ${ }^{+} \mathrm{CD} 11 \mathrm{c}^{+} \mathrm{CD} 11 \mathrm{~b}^{+}$ DCs in the small intestine promotes $\lg \mathrm{A}^{+}$cell differentiation by a retinoic acid-dependent process (52). Mice deficient in activation-induced cytidine deaminase, which leads to a loss of IgA-producing plasma cells, exhibit expansion of anaerobic, particularly segmented filamentous bacteria in the small intestine (53). TLR agonists can act directly on $B$ cells in the presence of transforming growth factor-beta (TGF- $\beta$ ) to promote IgA class switching in B cells (44). A population of tumor necrosis factor (TNF)/inducible nitric oxide synthase (iNOS)-producing DCs in the intestinal lamina propria produces nitric oxide and this leads to the induction of $B$ cell-activating factor of the TNF family (BAFF) and a proliferation-inducing ligand (APRIL), which promote activation-induced cytidine deaminase expression and IgA class switching (54). The development of TNF/iNOS-producing DCs requires TLR signaling, as the numbers of these cells in the lamina propria are reduced in MyD88-deficient and TLR2 $2^{-1-}$ TLR4 $^{-1}{ }^{-}$TLR9 $^{-1-}$ mice (55). As IgAcan have protective roles in immunity against pathogens, targeting cells including TNF/iNOS-producing DCs and TLR5-expressing DCs may have potential in vaccine development (56) and mucosal adjuvant discovery.

Th17 cells are a subset of Th cells that are implicated in protection against a number of extracellular pathogens, including the enteric pathogen Citrobacter rodentium (57) and in autoimmune conditions (58). Th17 cells are highly enriched and constitutively present in the intestinal lamina propria (59). This requires microbiota, as the numbers of Th17 cells are reduced in germ-free mice (60). The enteric pathogens Lysteria monocytogenes and Shigella flexneri have been found to signal to Th17 cells (61). Remarkably, however, the development of Th17 cells in the lamina propria has been found to be independent of TLR signaling, as it was intact in MyD88/TIR-domain-containing adapter-inducing interferon- $\beta$ (TRIF)-deficient mice. There were lower concentrations of luminal ATP and Th17 cells in germ-free mice, implicating the microbiota in both processes. Thus, both MyD88-dependent and -independent mechanisms for Th17 cell development probably exist. NLRP3 may be a mediator of commensal bacteria-induced Th17 responses in the intestine (56). In addition, $y \delta T$ cells, which are abundant in the intestinal epithelium (62), respond to stimulation with IL-1 and IL-23 by secreting IL-17, and act to amplify Th17 cell responses (63).

A major limitation of the development of mucosal vaccines is the lack of a safe and nontoxic human mucosal adjuvant. Most existing mucosal vaccines contain adjuvant (immunostimulant) from live-attenuated or inactivated microorganisms. Note that the strongest mucosal adjuvant for animals is the complete cholera toxin (CT). There are no added mucosal adjuvants in currently licensed vaccines.

Mucosal adjuvants must abrogate the normal tolerance induced by mucosal encounter, protect the antigens against expulsion and degradation, thereby allowing epithelial transport, and direct polarization. Microparticles instead of nanoparticles seem to be more suitable for the mucosal routes (Pérez O, Lastre M, Romeu B, Cuello M, Cabrera O, Balboa J, unpublished results). 


\section{The essence of formulation}

Apart from the type of adjuvant that is selected, the influence of formulation is also underestimated by many vaccinologists. Adjuvants have limited or no efficacy unless properly formulated. Formulation (e.g., oil-in-water, particle size, charge, etc.) is essential not only for the stability and the immunogenicity of the adjuvanted vaccines, but also to reduce their reactogenicity and to enhance vaccine potency (22). Most of this information is not published and remains as the know-how of companies, but one good example is related to particle size. Nonoparticles are recommended for parenteral formulation but microparticles for mucosal formulations. Nevertheless, this dogma is not always correct. It depends also on the composition of the adjuvant. Using adjuvant Finlay cochleate 1 (AFCo1), a proteoliposomederived cochleate of microparticle size, we induce not only mucosal but also parenteral immune responses (Lastre $\mathrm{M}$, unpublished results). The vaccine formulation must favor the IPz desired for a given antigen, the route of immunization expected to obtain a safe, stable, biodegraded product and an inexpensive production method. Furthermore, the ideally formulated adjuvant will be well defined chemically and physically to facilitate quality control that will ensure reproducible manufacturing and activity (22).

These are also the major concerns that affect the hurdle of translation from the preclinical stage vaccine to the clinical one, and it explains why most companies prefer alum, which is the most accepted and known adjuvant. Nevertheless, several companies recognize the need for new adjuvants and good formulations (64).

\section{The particular case of AFPL1 and AFCo1 adjuvants, proteo-cochleates}

These represent two of the Finlay adjuvant platforms or adjuvant family (AFPLx and AFCox). This platform is based on the following principles: they contain multiple IP (PAMPs) exhibiting synergistic activity, which make them a potent adjuvant. Proteo-cochleate (AFPL1-AFCo1) contains synergistic PAMPs like native LPS inserted in the lipid bilayer (this LPS is not free, which results in reduced toxicity), porins (Por A and B), and traces of bacterial DNA that contribute to IP activity. Consequently, it interacts with TLR4, TLR2, and TLR9, respectively $(4,65)$; the delivery system is based on non-living lipid structures extracted from the outer membrane of microorganisms (66) and on inclusion of immune IPz to induce the desired quality of immune response, associated with protective immunity. AFPL $1^{\mathrm{TM}}$ is derived from outer membrane proteins (forming vesicles) from serogroup $B N$. meningitidis and is already used as the main component of meningococcal $B C$ human vaccine, called VA-MENGOC-BC ${ }^{\mathrm{TM}}$ (40). It has been applied in more than 60 million doses in the world, mainly in Cuba and Latin America. It induces a preferential Th1 pattern of response characterized by IgG2a production in mice, and IgG1/3 production in humans, as well as increased IFN- $\gamma$, and no specific IgE or IL-4/5 (67). In addition, cross-priming presentation and in vivo CTL response are also induced (68); IP, DS, and IPz are in the same structure-forming particles (nano- or microparticles), but with similar components between each (AFPLx-AFCox) pair. Most adjuvant strategies are based on a combination of IP and DS. By contrast, our strategy is based on structures that contain all the adjuvant components together. This may explain why the Finlay Adjuvant Platform has exhibited high potency for several vaccines; the potential to be formulated with inserted or coadministered antigens/allergens (69); the capacity to induce persisting immune response or long-lasting memory (70); safety and maintained capacity of stimulation at extreme ages (old age and infants). VA-MENGOC-BC ${ }^{\mathrm{TM}}$ containing AFPL $1^{\mathrm{TM}}$ has been applied in more than 2 million doses to infants of 3 months of age, and AFCo1 proved to work safely in neonatal mice (71); the suitability for parenteral and mucosal routes (72); the possibility to increase coverage and compliance with the development of simultaneous vaccination strategies (STVS). STVS consists of the simultaneous use of a mucosal dose with a parenteral one, resulting in a systemic specific IgG response similar to two parenteral weekly spaced doses, and several weekly spaced mucosal doses (73); consistent production. AFPL1 ${ }^{\mathrm{TM}}$ has been produced for more than 20 years on the industrial scale under good manufacturing practice conditions at the Finlay Institute, and AFCo1 is currently at the stage of production development (74); proprietary products (75).

This Finlay adjuvant platform is at the forefront of the development of new vaccines, particularly new mucosal vaccines. Two decades of experience working with this vaccine adjuvant platform have allowed us to expand its potential use to vaccines against life-threatening human diseases as well as veterinary vaccines. SeveralAFPLx are in the stage of preclinical evaluation. Two AFCox, the AFCo1 and the AFCo2, have already been obtained (4). The potential use of AFCox derived from AFPLx for the mucosal route has recently completed the stage of experimental development.

\section{Current major problems in adjuvant research}

The first problem is that an adjuvant is not licensed in the absence of antigens. This is a consequence of the fact that adjuvant research is not viewed as an independent field in vaccinology. Therefore, each vaccine needs to go through all the phases of preclinical and clinical development whenever the adjuvant is changed, and the same adjuvant needs to be tested in each new formulation. Also, as mentioned above, the influence of the formulation is underestimated by many vaccinologists. Consequently, the evaluation of antigens as vaccine candidates has often been discontinued only because of a poor adjuvant selection or due to an unsuccessful formulation (21). To ensure that 
new and existing adjuvants will be available for use in vaccines and immunotherapy, the research and development protocol of adjuvant candidates should include checking for accessibility, cost of consumables and compliance with current and foreseeable regulatory issues. The development of candidate adjuvants should focus on establishing modular and transferable standard operating systems. Procedures and batch records for processing, production and fill-finishing, in addition to analytical tools, are essential. Procedures to evaluate the performance of the process and final product need to be established. At the same time, development should also attempt to remove problematic materials such as animal-derived components that might raise regulatory and comparability issues. Combining this view of raw material sourcing with attention to the cost of consumables should allow the development of sustainable adjuvant formulations that will have long product lifetimes without major changes in manufacturing and sourcing. Lastly, there are no human nontoxic mucosal adjuvants available, a problem that needs attention with high priority. Table 5 summarizes these major concerns.

\section{Adjuvants and adverse effects of vaccination}

Before licensure, vaccines are tested for safety and efficacy in preclinical tests performed in the laboratory, frequently with the use of animals, and in phase I clinical trials. Due to their experimental design (i.e., randomization, placebo-control, blinding), inferences on the causal relationship of an adverse event with the vaccine in such trials are relatively straightforward. Unfortunately, while helpful in providing data on common acute vaccine reactions (e.g., fever, swelling), pre-licensure trials usually cannot provide data on rare reactions (e.g., occurring $<1 / 1000$ doses), reactions with delayed onset (e.g., $\geq 30$ days after vaccinations), or reactions in specific subpopulations (e.g., infants are normally excluded from trials) (76). Postlicensure (also called post-marketing) evaluation of safety, after vaccines are administered to thousands or millions of persons, is therefore critical. Historically, such monitoring has relied on passive surveillance systems, like the Vaccine Adverse Event Reporting System, which may result in under-registration of rare adverse effects post vaccination. Therefore, immune epidemiological studies are needed to assess whether immunizations may involve risks for some susceptible individuals. Many serious adverse reactions to vaccines are a consequence of immune system stimulation, resulting in exacerbated inflammation, and, in some rare cases, autoimmune reactions. One well-known incident occurred in 1976, in the United States, when recipients of the 'swine influenza' vaccine were found to display an 8-fold

Table 5. Current issues in adjuvant research.

1 Adjuvants are considered by regulatory agencies as an integral part of the finished vaccine product. Consequently, adjuvants are not licensed per se, including those that were used with co-administered antigens.

2 There is no international center for comparison of adjuvants and vaccine formulations. Consequently, we need to accept the little and incomplete information available. In addition, potential adjuvant-antigen combinations have not been developed because of the high costs and efforts involved in gaining FDA or EMEA approval for each adjuvant-antigen combination.

3 A comprehensive overview, or comparative studies of adjuvants using model antigens and low and high immunogenic antigens are not available.

4 Lack of access to promising new adjuvants essential for new vaccines. Consequently, both big and small vaccine companies focus on their own adjuvant research programs.

5 Adjuvant development occurs mainly by big private vaccine companies, and therefore is bound to patent rights, and is not available for commercialization. Consequently, they are not available to the public sector or small companies.

6 Most vaccine companies keep their adjuvant formulations proprietary until the adjuvant is registered with a potential vaccine product. Consequently, this limits the development of the adjuvant for other vaccine applications.

7 New vaccines against life-threatening diseases (malaria, TB, and HIV) and neglected tropical diseases have been conducted with non-optimized adjuvants. They either use alum (that induces only strong antibody responses) or water-in-oil emulsions, which are the only freely available adjuvants.

8 High costs are involved in developing novel adjuvants. Consequently, some otherwise viable antigens have been abandoned as candidates for new vaccines due to lack of the correct adjuvant. This results in a significant waste of resources from public and private sources.

9 Lack of understanding that future vaccines need to be designed using alternative routes of immunization, particularly the mucosal routes. Consequently, no mucosal adjuvant exists, and only a few promising ones have been studied.

10 Lack of realization that the polarization of the immune response is critical for induction of protection. Consequently, the selection of the adjuvant continues to be empirical for some vaccines.

11 The challenge is to establish a system that provides open access to adjuvants and adjuvant information to non-profit and profit initiatives, without impairing the freedom-of-operation of the adjuvant owner.

FDA = Food and Drug Administration; EMEA = European Medicines Agency; TB = tuberculosis; HIV = human immunodeficiency virus. 
increased risk of developing Guillain-Barré syndrome when compared to non-vaccinees $(77,78)$. Other examples of such adverse effects range from hepatitis $B$ vaccine-associated multiple sclerosis (79) to infant immunization-associated type 1 diabetes mellitus (80). Some human vaccine withdrawals following serious adverse effects have occurred. In one example, the adjuvant labile enterotoxin B (LTB) subunit has been proven to have affinity for the central nervous system ganglioside GM1, a phenomenon that is probably responsible for the facial palsy seen when this molecule is administered nasally (81). It is obvious that several barriers must be overcome to meet the demands for new adjuvants. Unacceptable side effects and toxicity are still important barriers for most candidates, particularly for the development of pediatric vaccines. In addition, regulatory standards for adjuvant approval have improved substantially since the approval of alum (21). Many products have been proposed as vaccine adjuvants, but have been rejected because of safety concerns. Extensive research is therefore needed either to understand how to exploit current adjuvants safely or to explore novel products with better safety profiles.

\section{Changes in the perception of adjuvant research}

The field of vaccinology is currently in a golden era, including the field of adjuvant research. This can be measured by the increase in perception of the important role of adjuvants for improving the existing and novel vaccines (reviewed in Ref. 6). This perception is at the level not only of big pharmaceutical companies involved in human vaccines, like GlaxoSmithKline and Novartis, but also at the level of small companies, like Finlay SA, of regulatory agencies, like the European Agency for the European Medicines Agency and the Cuban Center for the State Control of Medicines Quality, of non-profit organizations such as the Global Adjuvant Development Initiative and the Mucosal Vaccines for Poverty Related Diseases, and moreover, in the European Commission and World Health Organization.

\section{References}

1. Jenner EE. The three original publications on vaccination against smallpox. Vol. 38, Part 4. The Harvard Classics [Internet] Bartleby com http://www.bartleby.com/38/4/; 2010.

2. Schijns VE. Immunological concepts of vaccine adjuvant activity. Curr Opin Immunol 2000; 12: 456-463.

3. O'Hagan DT, Valiante NM. Recent advances in the discovery and delivery of vaccine adjuvants. Nat Rev Drug Discov 2003; 2: 727-735.

4. Perez O, Lastre M, Bracho G, del Campo J, Zayas C, Acevedo R, et al. Natural Neissera derive proteoliposome and cochleate as potent vaccine adjuvants. Pharmacologyonline 2006; 3: 762-764

5. Kenney RT, Edelman R. Survey of human-use adjuvants. Expert Rev Vaccines 2003; 2: 167-188.

6. Harandi AM, Davies G, Olesen OF. Vaccine adjuvants: scientific challenges and strategic initiatives. Expert Rev Vaccines 2009; 8: 293-298.

7. Schenten D, Medzhitov R. The control of adaptive immune responses by the innate immune system. Adv Immunol 2011; 109: 87-124.

8. Huang DB, Wu JJ, Tyring SK. A review of licensed viral vaccines, some of their safety concerns, and the advances in the development of investigational viral vaccines. J Infect 2004; 49: 179-209.

9. Perrie Y, Mohammed AR, Kirby DJ, McNeil SE, Bramwell VW. Vaccine adjuvant systems: enhancing the efficacy of sub-unit protein antigens. Int J Pharm 2008; 364: 272-280.

10. Adkins B, Leclerc C, Marshall-Clarke S. Neonatal adaptive immunity comes of age. Nat Rev Immunol 2004; 4: 553564.

11. Perlmutter RM, Hansburg D, Briles DE, Nicolotti RA, Davie JM. Subclass restriction of murine anti-carbohydrate antibodies. J Immunol 1978; 121: 566-572.

12. Barrett DJ, Ayoub EM. IgG2 subclass restriction of antibody to pneumococcal polysaccharides. Clin Exp Immunol 1986;
63: $127-134$.

13. Klein Klouwenberg P, Bont L. Neonatal and infantile immune responses to encapsulated bacteria and conjugate vaccines. Clin Dev Immunol 2008; 2008: 628963.

14. Lee HH, Hoeman CM, Hardaway JC, Guloglu FB, Ellis JS, Jain $\mathrm{R}$, et al. Delayed maturation of an IL-12-producing dendritic cell subset explains the early Th2 bias in neonatal immunity. J Exp Med 2008; 205: 2269-2280.

15. Burgess MA, Mclntyre PB. Vaccines and the cold chain: is it too hot ... or too cold? Med J Aust 1999; 171: 82.

16. Reed SG, Bertholet S, Coler RN, Friede M. New horizons in adjuvants for vaccine development. Trends Immunol 2009; 30: 23-32.

17. Hem SL, Hogenesch H. Relationship between physical and chemical properties of aluminum-containing adjuvants and immunopotentiation. Expert Rev Vaccines 2007; 6: 685698.

18. Brewer JM, Conacher M, Hunter CA, Mohrs M, Brombacher $\mathrm{F}$, Alexander J. Aluminium hydroxide adjuvant initiates strong antigen-specific Th2 responses in the absence of IL-4- or IL-13-mediated signaling. J Immunol 1999; 163: 6448-6454.

19. Kool M, Soullie T, van Nimwegen M, Willart MA, Muskens $\mathrm{F}$, Jung $\mathrm{S}$, et al. Alum adjuvant boosts adaptive immunity by inducing uric acid and activating inflammatory dendritic cells. J Exp Med 2008; 205: 869-882.

20. Eisenbarth SC, Colegio OR, O'Connor W, Sutterwala FS, Flavell RA. Crucial role for the Nalp3 inflammasome in the immunostimulatory properties of aluminium adjuvants. Nature 2008; 453: 1122-1126.

21. Sun H, Pollock KG, Brewer JM. Analysis of the role of vaccine adjuvants in modulating dendritic cell activation and antigen presentation in vitro. Vaccine 2003; 21: 849-855.

22. Shi Y, Evans JE, Rock KL. Molecular identification of a danger signal that alerts the immune system to dying cells. 
Nature 2003; 425: 516-521.

23. MacLeod MK, McKee AS, David A, Wang J, Mason R, Kappler JW, et al. Vaccine adjuvants aluminum and monophosphoryl lipid A provide distinct signals to generate protective cytotoxic memory CD8 T cells. Proc Natl Acad Sci U S A 2011; 108: 7914-7919.

24. Li H, Nookala S, Re F. Aluminum hydroxide adjuvants activate caspase- 1 and induce IL-1 beta and IL-18 release. $J$ Immunol 2007; 178: 5271-5276.

25. Franchi L, Nunez G. The Nlrp3 inflammasome is critical for aluminium hydroxide-mediated IL-1beta secretion but dispensable for adjuvant activity. Eur J Immunol 2008; 38: 2085-2089.

26. Adachi O, Kawai T, Takeda K, Matsumoto M, Tsutsui H, Sakagami M, et al. Targeted disruption of the MyD88 gene results in loss of IL-1- and IL-18-mediated function. Immunity 1998; 9: 143-150.

27. Gavin AL, Hoebe K, Duong B, Ota T, Martin C, Beutler B, et al. Adjuvant-enhanced antibody responses in the absence of Toll-like receptor signaling. Science 2006; 314: 1936-1938.

28. Pollock KG, Conacher M, Wei XQ, Alexander J, Brewer JM. Interleukin-18 plays a role in both the alum-induced $T$ helper 2 response and the T helper 1 response induced by alumadsorbed interleukin-12. Immunology 2003; 108: 137-143.

29. Flach TL, Ng G, Hari A, Desrosiers MD, Zhang P, Ward SM, et al. Alum interaction with dendritic cell membrane lipids is essential for its adjuvanticity. Nat Med 2011; 17: 479-487.

30. Marichal T, Ohata K, Bedoret D, Mesnil C, Sabatel C, Kobiyama $\mathrm{K}$, et al. DNA released from dying host cells mediates aluminum adjuvant activity. Nat Med 2011; 17: 996-1002.

31. Bungener L, Geeraedts F, Ter Veer W, Medema J, Wilschut J, Huckriede A. Alum boosts TH2-type antibody responses to whole-inactivated virus influenza vaccine in mice but does not confer superior protection. Vaccine 2008; 26: 23502359.

32. Falsey AR, Walsh EE, Capellan J, Gravenstein S, Zambon $M$, Yau $E$, et al. Comparison of the safety and immunogenicity of 2 respiratory syncytial virus (rsv) vaccines - nonadjuvanted vaccine or vaccine adjuvanted with alum - given concomitantly with influenza vaccine to high-risk elderly individuals. J Infect Dis 2008; 198: 1317-1326.

33. Baldridge JR, Crane RT. Monophosphoryl lipid A (MPL) formulations for the next generation of vaccines. Methods 1999; 19: 103-107.

34. Sierra GV, Campa HC, Varcacel NM, Garcia IL, Izquierdo $\mathrm{PL}$, Sotolongo PF, et al. Vaccine against group B Neisseria meningitidis: protection trial and mass vaccination results in Cuba. NIPH Ann 1991; 14: 195-207.

35. Sotolongo F, Campa C, Casanueva V, Fajardo EM, Cuevas IE, Gonzalez N. Cuban Meningococcal BC Vaccine: experiences and contributions from 20 Years of application. MEDICC Rev 2007; 9: 16-22.

36. Wheeler AW, Woroniecki SR. Allergy vaccines - new approaches to an old concept. Expert Opin Biol Ther 2004; 4: 1473-1481.

37. Ott G, Barchfeld GL, Van Nest G. Enhancement of humoral response against human influenza vaccine with the simple submicron oil/water emulsion adjuvant MF59. Vaccine 1995; 13: $1557-1562$.

38. Wadman M. Race is on for flu vaccine. Nature $2005 ; 438$ : 23.

39. Carter NJ, Plosker GL. Prepandemic influenza vaccine
H5N1 (split virion, inactivated, adjuvanted) [Prepandrix]: a review of its use as an active immunization against influenza A subtype H5N1 virus. BioDrugs 2008; 22: 279-292.

40. Garcon N, Chomez P, Van Mechelen M. GlaxoSmithKline adjuvant systems in vaccines: concepts, achievements and perspectives. Expert Rev Vaccines 2007; 6: 723-739.

41. Gluck R, Burri KG, Metcalfe I. Adjuvant and antigen delivery properties of virosomes. Curr Drug Deliv 2005; 2: 395-400.

42. Creagh EM, O'Neill LA. TLRs, NLRs and RLRs: a trinity of pathogen sensors that co-operate in innate immunity. Trends Immunol 2006; 27: 352-357.

43. Mann JF, Acevedo R, Campo JD, Perez O, Ferro VA. Delivery systems: a vaccine strategy for overcoming mucosal tolerance? Expert Rev Vaccines 2009; 8: 103-112.

44. Barbosa T, Rescigno M. Host-bacteria interactions in the intestine: homeostasis to chronic inflammation. Wiley Interdiscip Rev Syst Biol Med 2010; 2: 80-97.

45. Hooper LV, Wong MH, Thelin A, Hansson L, Falk PG, Gordon JI. Molecular analysis of commensal host-microbial relationships in the intestine. Science 2001; 291: 881-884.

46. Slack E, Hapfelmeier S, Stecher B, Velykoredko Y, Stoel M, Lawson MA, et al. Innate and adaptive immunity cooperate flexibly to maintain host-microbiota mutualism. Science 2009; 325: 617-620.

47. Franchi L, Park JH, Shaw MH, Marina-Garcia N, Chen G, Kim YG, et al. Intracellular NOD-like receptors in innate immunity, infection and disease. Cell Microbiol 2008; 10: 1-8.

48. Barreau F, Meinzer U, Chareyre F, Berrebi D, Niwa-Kawakita $M$, Dussaillant $M$, et al. CARD15/NOD2 is required for Peyer's patches homeostasis in mice. PLoS One 2007; 2: e523.

49. Kobayashi KS, Chamaillard M, Ogura Y, Henegariu O, Inohara N, Nunez G, et al. Nod2-dependent regulation of innate and adaptive immunity in the intestinal tract. Science 2005; 307: 731-734.

50. Viala J, Chaput C, Boneca IG, Cardona A, Girardin SE, Moran AP, et al. Nod1 responds to peptidoglycan delivered by the Helicobacter pylori cag pathogenicity island. Nat Immunol 2004; 5: 1166-1174.

51. Hall JA, Bouladoux N, Sun CM, Wohlfert EA, Blank RB, Zhu $Q$, et al. Commensal DNA limits regulatory $T$ cell conversion and is a natural adjuvant of intestinal immune responses. Immunity 2008; 29: 637-649.

52. Uematsu S, Fujimoto K, Jang MH, Yang BG, Jung YJ, Nishiyama M, et al. Regulation of humoral and cellular gut immunity by lamina propria dendritic cells expressing Tolllike receptor 5. Nat Immunol 2008; 9: 769-776.

53. Fagarasan $\mathrm{S}$, Muramatsu M, Suzuki K, Nagaoka $\mathrm{H}$, Hiai $\mathrm{H}$, Honjo T. Critical roles of activation-induced cytidine deaminase in the homeostasis of gut flora. Science 2002; 298: 1424-1427.

54. Tezuka $\mathrm{H}$, Abe $\mathrm{Y}$, Iwata $\mathrm{M}$, Takeuchi $\mathrm{H}$, Ishikawa $\mathrm{H}$, Matsushita $\mathrm{M}$, et al. Regulation of IgA production by naturally occurring TNF/iNOS-producing dendritic cells. Nature 2007; 448: 929-933.

55. Fitzgerald KA, Palsson-McDermott EM, Bowie AG, Jefferies CA, Mansell AS, Brady G, et al. Mal (MyD88-adapter-like) is required for Toll-like receptor-4 signal transduction. Nature 2001; 413: 78-83.

56. Ryan ET, Calderwood SB. Cholera vaccines. Clin Infect Dis 2000; 31: 561-565.

57. Mangan PR, Harrington LE, O'Quinn DB, Helms WS, Bul- 
lard DC, Elson CO, et al. Transforming growth factor-beta induces development of the $\mathrm{T}(\mathrm{H}) 17$ lineage. Nature 2006; 441: 231-234.

58. Weaver CT, Hatton RD, Mangan PR, Harrington LE. IL-17 family cytokines and the expanding diversity of effector $T$ cell lineages. Annu Rev Immunol 2007; 25: 821-852.

59. Ivanov II, McKenzie BS, Zhou L, Tadokoro CE, Lepelley A, Lafaille JJ, et al. The orphan nuclear receptor RORgammat directs the differentiation program of proinflammatory IL-17+ T helper cells. Cell 2006; 126: 1121-1133.

60. Atarashi K, Nishimura J, Shima T, Umesaki Y, Yamamoto $\mathrm{M}$, Onoue $\mathrm{M}$, et al. ATP drives lamina propria $\mathrm{T}(\mathrm{H}) 17$ cell differentiation. Nature 2008; 455: 808-812.

61. Willingham SB, Bergstralh DT, O'Connor W, Morrison AC, Taxman DJ, Duncan JA, et al. Microbial pathogen-induced necrotic cell death mediated by the inflammasome components CIAS1/cryopyrin/NLRP3 and ASC. Cell Host Microbe 2007; 2: 147-159.

62. Hayday A, Tigelaar R. Immunoregulation in the tissues by gammadelta T cells. Nat Rev Immunol 2003; 3: 233-242.

63. Sutton CE, Lalor SJ, Sweeney CM, Brereton CF, Lavelle EC, Mills $\mathrm{KH}$. Interleukin-1 and IL-23 induce innate IL-17 production from gammadelta T cells, amplifying Th17 responses and autoimmunity. Immunity 2009; 31: 331-341.

64. Rappuoli R. Bridging the knowledge gaps in vaccine design. Nat Biotechnol 2007; 25: 1361-1366.

65. Perez O, Lastre M, Cabrera O, del Campo J, Bracho G, Cuello $M$, et al. New vaccines require potent adjuvants like AFPL1 and AFCo1. Scand J Immunol 2007; 66: 271-277.

66. Perez O, Bracho G, Lastre M, Zayas C, Gonzalez D, Gil D, et al. Proteliposome-derived cochleate as an immunomodulator for nasal vaccine. Vaccine 2006; 24 (Suppl 2): S2-S3.

67. Bracho G, Zayas C, Wang L, Coppel R, Perez O, Petrovsky N. AFCo1, a meningococcal B-derived cochleate adjuvant, strongly enhances antibody and T-cell immunity against Plasmodium falciparum merozoite surface protein 4 and 5 . Malar J 2009; 8: 35.

68. Rodriguez T, Perez O, Menager N, Ugrinovic S, Bracho G, Mastroeni P. Interactions of proteoliposomes from serogroup B Neisseria meningitidis with bone marrow-derived dendritic cells and macrophages: adjuvant effects and antigen delivery. Vaccine 2005; 23: 1312-1321.

69. Lastre M, Perez O, Labrada A, Bidot I, Perez J, Bracho G, et al. Bacterial derived proteoliposome for allergy vaccines. Vaccine 2006; 24 (Suppl 2): S2-S5.

70. Pérez O, Lastre M, Lapinet J, Pérez A, Díaz M, Zayas C, et al. Long-lasting cellular immune response in babies, chil- dren, and pre-teenagers vaccinated with a proteoliposome based anti-meningococcal BC vaccine. Inmunología 2002; 20: 177-183.

71. Balboa JA, Romeu B, Cuello M, Zayas C, del Campo J, González E, et al. Intranasal immunization with AFCo1 induce systemic, mucosal and memory immune response in neonatal mice. VacciMonitor 2012.

72. del Campo J, Lastre M, Bracho G, Rodriguez T, Gil D, Zayas $\mathrm{C}$, et al. Immunological evaluation of bacterial derived cochleate and proteoliposome as mucosal adjuvants. Vaccine 2006; 24 (Suppl 2): S2.

73. Pérez O, González E, Romeu B, del Campo J, Acevedo $\mathrm{R}$, Lastre $\mathrm{M}$, et al. Vacunas unitemporales. Patent applied OCPI, CU/P/2008/215. November 19, 2008.

74. Zayas C, Bracho G, Lastre M, Gonzalez D, Gil D, Acevedo R, et al. Scale up of proteoliposome derived cochleate production. Vaccine 2006; 24 (Suppl 2): S2-S5.

75. Pérez Martín OG, Bracho Grandos GR, Lastre González M de SJB, Sierra González VG, Campa Huergo C, Mora González N, et al. Método de obtención de estructuras cocleares. Composiciones vacúnales y adyuvantes basados en estructuras cocleares y sus intermediarios. Available at [http://www.ocpi.cu/boletines/boletin_244_ago_2008.pdf].

76. Chen RT, Pless R, Destefano F. Epidemiology of autoimmune reactions induced by vaccination. J Autoimmun 2001; 16: 309-318.

77. Schonberger LB, Bregman DJ, Sullivan-Bolyai JZ, Keenlyside RA, Ziegler DW, Retailliau HF, et al. Guillain-Barré syndrome following vaccination in the National Influenza Immunization Program, United States, 1976-1977. Am J Epidemiol 1979; 110: 105-123.

78. Lasky T, Terracciano GJ, Magder L, Koski CL, Ballesteros M, Nash D, et al. The Guillain-Barré syndrome and the 19921993 and 1993-1994 influenza vaccines. N Engl J Med 1998; 339: 1797-1802.

79. Herroelen L, de Keyser J, Ebinger G. Central-nervoussystem demyelination after immunisation with recombinant hepatitis B vaccine. Lancet 1991; 338: 1174-1175.

80. Classen DC, Classen JB. The timing of pediatric immunization and the risk of insulin-dependent diabetes mellitus. Infectious diseases in clinical practice. http://journals.Iww. com/infectdis/Fulltext/1997/06070/The_Timing_of_Pediatric_Immunization_and_the_Risk.7.aspx.

81. Zurbriggen R, Metcalfe IC, Gluck R, Viret JF, Moser C. Nonclinical safety evaluation of Escherichia coli heat-labile toxin mucosal adjuvant as a component of a nasal influenza vaccine. Expert Rev Vaccines 2003; 2: 295-304. 